\title{
Design of Portable Phototherapy using PL-S UVB Lamp for Psoriasis Therapy
}

\author{
Fitria Hidayanti, Sunartoto Gunadi, M. Syafaat
}

\begin{abstract}
This research aims to design portable phototherapy using PL-S UVB lamp. The transformer DC power supply range used is step down transformer with 220 Volt primary input and 12 volt secondary output. The series of Driver Relay serves to control the mechanical relay in the on-off position, which corresponds to the changes received by the counting circuit, the circuit uses $a \mathrm{BC}$ 547A transistor and a $12 \mathrm{~V} / 5$ pole $\mathrm{DC}$ relay and the diode used IN 4002/ IN4004. Resistance in this relay of $400 \Omega$. From the measurement results using digital multimeter obtained the voltage value in the IC LM7812 of 12.11 Volt and on IC LM7805 of 5.02 Volt. Ultraviolet radiation spectrum can penetrate the base layer of the dermis. Ultraviolet rays $B$ can penetrate the base layer of epidermis skin.
\end{abstract}

Keywords : design, portable, phototherapy, UVB, psoriasis.

\section{INTRODUCTION}

Every year people with especially psoriasis disease are increasing [1]. With the increasing number of psoriasis sufferers and the heightened human awareness of health, various efforts continue to overcome the disease [2]. Some therapies to overcome the disease include photochemotherapy, metotrexathe and retinoids to clean the surface of the affected skin psoriasis, so that the skin returns to normal $[3,4]$. However, in certain periods of such psoriasis may reoccur.

Based on information from WHO that the number of psoriasis sufferers in each country reaches $1-3 \%$ of the total population [5]. Meanwhile, according to Indonesian Psoriasis Foundation, the number of psoriasis sufferers in Indonesia reaches about 2-6 million people [6].

Ultraviolet therapy [7-9] that uses artificial ultraviolet rays can treat psoriasis and has a return period of more than 50 years if the treatment is done in a fix dose, distance and precise timing, where a large dose is highly dependent on human skin type, age of the patient and disease conditions when treated [10, 11].

Currently in Indonesia, the number of psoriasis patients treatment using ultraviolet phototherapy tends to increase in accordance with increased human consciousness in healthy living [12, 13]. However this is not balanced with the

Revised Manuscript Received on April 25, 2020.

* Correspondence Author

Fitria Hidayanti*, Engineering Physics Department, Universitas Nasional, Jakarta, Indonesia. Email: fitriahidayanti@gmail.com

Sunartoto Gunadi, Professor at Engineering Physics Department, Universitas Nasional.

M. Syafaat, Bachelor Degree at Engineering Physics Department, Universitas Nasional.

(C) The Authors. Published by Blue Eyes Intelligence Engineering and Sciences Publication (BEIESP). This is an open access article under the CC BY-NC-ND license (http://creativecommons.org/licenses/by-nc-nd/4.0/) improvement of equipment and the improvement of the comfort services of patients who perform therapy with ultraviolet phototherapy, where the equipment imports is expensive and the high technological dependence [14].

Based on the background above, the authors want to give a contribution to the Indonesian people in terms of healing psoriasis disease, by means of design and manufacture a device that can cure psoriasis disease thus the sufferer psoriasis in Indonesian can be decreased.

Phototherapy equipment previously created in a large size, requiring patients to conduct therapy in the hospital. Becase the phototherapy equipment is difficult to carry, patients psoriasis who are in a part that is difficult to be treated by non-portable phototherapy equipment will be easily treated by portable phototherapy equipment. Patients psoriasis located in any part of the body can be reached easily by portable phototherapy equipment so that psoriasis or vitiligo that is on the part of the body is visible, such as in the face, hands, neck etc. The sufferer who may be embarrassed out of the house for treatment to the hospital, then with the creation of portable phototherapy equipment, sufferers can call a doctor to do therapy in the patient's home.

\section{MATERIALS AND METHOD}

\section{A. Diagram Block System}

The design of portable phototherapy equipment using the PL-S UVB lamps is realised according to the components (Fig. 1).

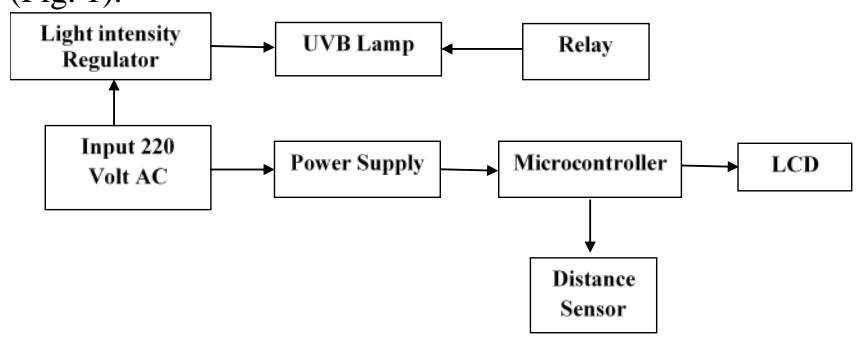

Fig. 1.Diagram Block System

\section{B. Power Supply Circuit}

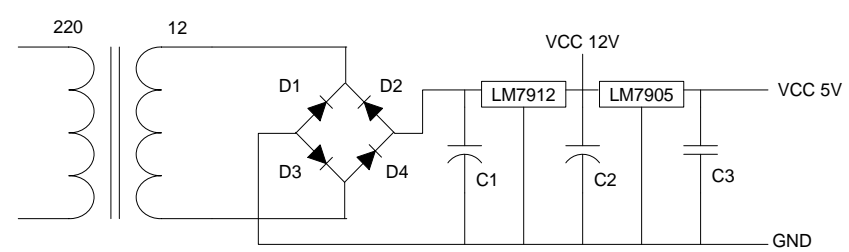

Fig. 2. Power Supply Circuit

Published By:

Blue Eyes Intelligence Engineering

\& Sciences Publication

DOI: 10.35940/ijeat.D7412.049420

Journal Website: www.ijeat.org 


\section{Design of Portable Phototherapy using PL-S UVB Lamp for Psoriasis Therapy}

The transformer DC power supply range used is step down transformer with 220 Volt primary input and 12 volt secondary output. Terminal 0 Volt and 220 volt on the primary side.

While the terminals 0 volt, 5 Volt and 12 volt on the side of the secondary are connected with a range of bridge rectifier. The type of rectifier used is developed from the IN 4002 type diode. This diode has a current $1 \mathrm{~A}$ and peak current of $30 \mathrm{~A}$, while the ability to withstand 50 Volt voltages.

DC voltage after passing the capacitor filter is almost close to the flat, but this voltage will be affected from the ups and downs of the change of load. To further solidify the output voltage of this DC power supply then used a series of integration in the form of positive IC regulator LM 7812 and LM 7805. Capacitors C1 and C2 in Fig. 2 serve as riple reducer of electric mesh back and forth. While C3 serves to correct transient responses to the output voltage as the load increases.

\section{Relay Driver Circuit}

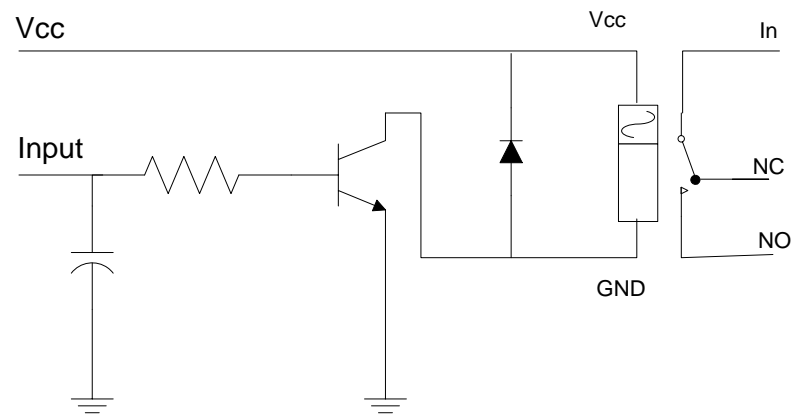

Fig. 3.Relay Driver Circuit

The series of driver relay (Fig. 3) serves to control the mechanical relay in the on-off position, which corresponds to the changes received by the counting circuit, the circuit uses a BC 547A transistor and a $12 \mathrm{~V} / 5$ pole DC relay and the diode used IN 4002/ IN4004. Resistance in this relay of $400 \Omega$. Meanwhile, BC 547A switching transistors have a maximum collector current of $\mathrm{I}_{\mathrm{c}}$ (maximum) is $200 \mathrm{~mA}$ with a strengthening (HFE) of 250. To make the transistor work as a switch then the base should be supply current or voltage.

Tha algorithm of portable phototherapy can be seen in Fig. 4.

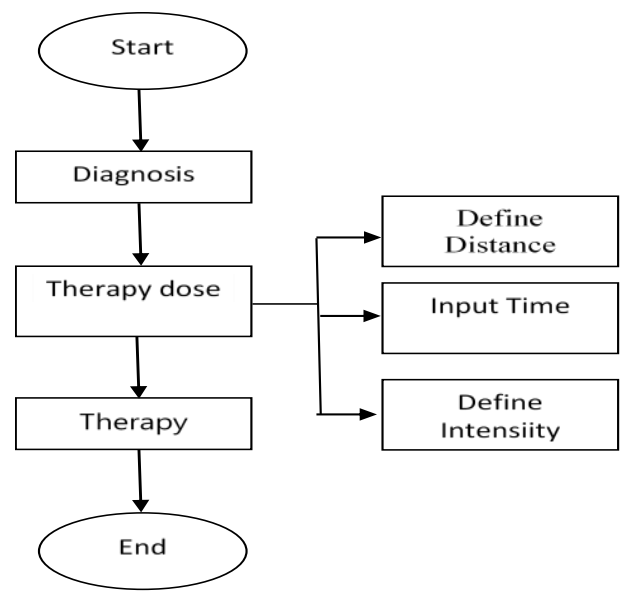

Fig. 4. Algorithm Portable Phototherapy

\section{RESULTS AND DISCUSSION}

\section{A. Power Supply Circuit Testing}

In the test of the DC power supply circuit measuring device used to measure the amount of voltage used by digital Multimeter, this is done to know if the power supply circuit can produce the expected voltage, which is $12 \mathrm{~V}$ and $5 \mathrm{~V}$. Testing the power supply circuit can be seen in Fig. 5 below.

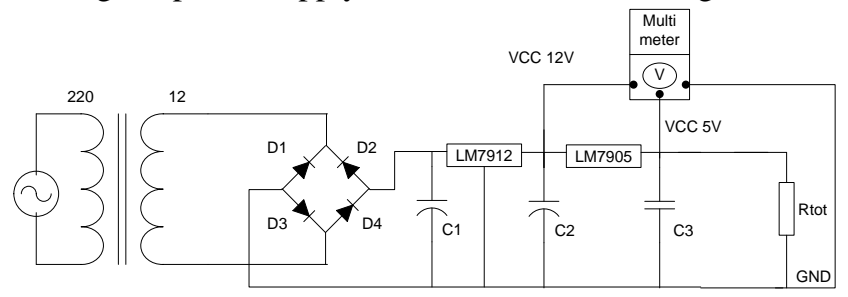

Fig. 5.Power Supply Circuit Measurement

From the measurement results using digital multimeter obtained the voltage value in the IC LM7812 of 12.11 Volt and on IC LM7805 of 5.02 Volt (Fig. 6). From the results of the measurements can be seen that the output IC LM7812 and IC LM7805 voltage produced is $12.11 \mathrm{~V}$ and $5.02 \mathrm{~V}$ which is theoretically supposed to be $12 \mathrm{~V}$ and $5 \mathrm{~V}$. The difference in this value can be due to the level of accuracy of the measuring instrument used is $0.1 \%$ and less than the ideal value of the computed voltage that is influenced by prisoners in the Alar measure acting as an additional burden in the calculation is not a calculated variable.
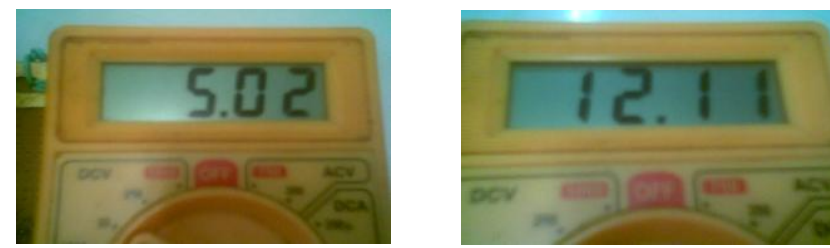

Fig. 6.Multimeter Measurement

\section{B. Relay Driver Circuit Testing}

The driver relay testing can be seen in Fig. 7 below.

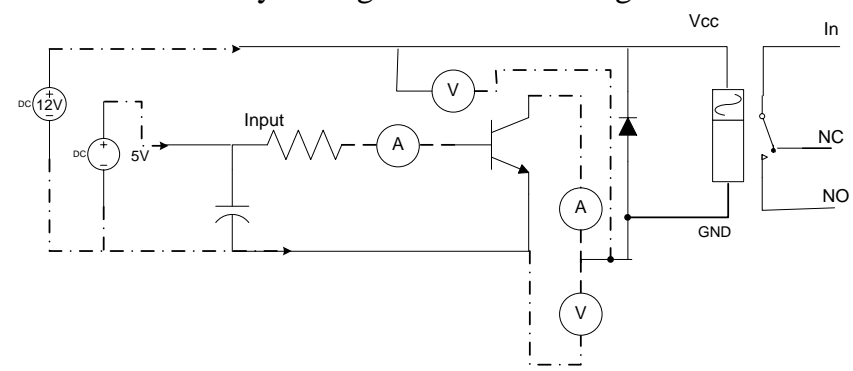

Fig. 7.Relay Driver Circuit Testing

This test uses 12 Volt and 5 Volt DC voltage sources, this is done to see if the relay to be used works well. 12 Volt voltage is given at the source of the relay voltage and voltage 5 Volt is given on the input. When inputs are given the voltage it will drain the current into the transistor causing the transistor to work like a switch that connects the collector's feet to the emitter, this makes the relay foot connected to the ground so the relay works well. Measurement result can be showed at Table I follows.

Table- I: Measurement of Relay Driver Circuit

\begin{tabular}{|l|c|c|}
\hline \multicolumn{1}{|c|}{ Measurement } & Calculation & Relay \\
Published By: \\
Blue Eyes Intelligence Engineering \\
\& Sciences Publication \\
(C) Copyright: All rights reserved.
\end{tabular}




\begin{tabular}{|c|c|c|c|c|c|c|c|}
\hline & $\begin{array}{c}\mathbf{A}_{\mathbf{1}} \\
\mathbf{( m A )}\end{array}$ & $\begin{array}{c}\mathbf{A}_{\mathbf{2}} \\
\mathbf{( m A )}\end{array}$ & $\begin{array}{c}\mathbf{V}_{\mathbf{1}} \\
\mathbf{( V )}\end{array}$ & $\mathbf{V}_{\mathbf{2}} \mathbf{( V )}$ & $\begin{array}{c}\mathbf{A}_{\mathbf{1}} \\
\mathbf{( m A )}\end{array}$ & $\begin{array}{c}\mathbf{A}_{\mathbf{2}} \\
\mathbf{( m A )}\end{array}$ & \\
\hline 0 & 0 & 0 & 0 & 12.11 & 0 & 0 & OFF \\
\hline 5.02 & 0.11 & 27.55 & 11.04 & 1.48 & 0.1107 & 27.675 & ON \\
\hline
\end{tabular}

For the 2 Ampere trigger test series, the value of the resistance in the relay is $400 \Omega$, the $h f e$ transistor BC 547A is 259 . While $V_{\text {in }}$ as 5.02 volts and the resistance $39 \mathrm{~K} \Omega$.

$A_{1}=\frac{5.02-0.7}{39000}=\frac{4.32 \mathrm{~V}}{39000}=\frac{4320}{39000}=0.1107 \mathrm{~mA}$

\section{$A_{2}=0.1107 \times 250=27.675 \mathrm{~mA}$}

The value of $I_{b}$ and $I_{c}$ have small differences. The difference in $I_{c}$ values between measurements and calculations is caused by the difference in the value of $I_{b}$ gained by calculation and Measurement due to determining of current passing the transistor is determined by a current that enters the base transistor multiplied by a large $h f e$ of the transistor.

\section{Ultrasonic Ping Sensor Circuit Testing}

In principle, distance measurement is done by measuring distance from the lamp to the patient's skin. Thus the small mistake that occurs in such measurements is dependent on the small distance measured by the PING sensor. The test is done on an object with a flat surface with the distance between the PING sensor and the surface of the purifier between $10 \mathrm{~cm}$ to $50 \mathrm{~cm}$ with a $5 \mathrm{~cm}$ interval. The Data obtained can be seen in Table II below.

Table- II: Ultrasonic Ping Sensor Circuit Testing

\begin{tabular}{|c|c|c|c|}
\hline \multirow{2}{*}{$\begin{array}{c}\text { Comparison } \\
\begin{array}{c}\text { Measurem ent } \\
(\mathbf{c m})\end{array}\end{array}$} & $\begin{array}{c}\text { Mata 1 } \\
\left(\mathbf{x}_{\mathbf{1}}\right)\end{array}$ & $\begin{array}{c}\text { Data 2 } \\
\left(\mathbf{x}_{\mathbf{2}}\right)\end{array}$ & $\begin{array}{c}\text { Data 3 } \\
\left(\mathbf{x}_{3}\right)\end{array}$ \\
\cline { 2 - 4 } & 10.00 & 10.10 & 10.00 \\
\hline 10 & 15.20 & 15.00 & 15.00 \\
\hline 15 & 19.01 & 19.30 & 19.01 \\
\hline 20 & 25.02 & 25.00 & 24.99 \\
\hline 30 & 29.94 & 30.01 & 30.00 \\
\hline 35 & 34.58 & 34.98 & 35.03 \\
\hline 40 & 40.29 & 40.02 & 40.20 \\
\hline 45 & 45.36 & 45.10 & 45.20 \\
\hline 50 & 49.98 & 50.01 & 50.30 \\
\hline
\end{tabular}

Based on the test data obtained as in Table II can be done the following calculations as shown in Table III.

\begin{tabular}{|c|c|c|c|}
\hline \multicolumn{4}{|c|}{ Table- III: Calculation Result } \\
\hline $\begin{array}{c}\text { Reference } \\
\text { (cm) }\end{array}$ & $\begin{array}{c}\text { Measurement } \\
\text { (cm) }\end{array}$ & $\begin{array}{l}\text { Average } \\
\text { (cm) }\end{array}$ & $\begin{array}{c}\text { Deviation } \\
\text { (cm) }\end{array}$ \\
\hline \multirow{3}{*}{10} & 10 & \multirow{3}{*}{10.03} & 0.03 \\
\hline & 10.1 & & 0.07 \\
\hline & 10 & & 0.03 \\
\hline \multirow{3}{*}{15} & 15.2 & \multirow{3}{*}{15.06} & 0.14 \\
\hline & 15 & & 0.06 \\
\hline & 15 & & 0.06 \\
\hline \multirow{3}{*}{20} & 19.01 & \multirow{3}{*}{19.1} & 0.09 \\
\hline & 19.3 & & 0.2 \\
\hline & 19.01 & & 0.09 \\
\hline \multirow{3}{*}{25} & 25.02 & \multirow{3}{*}{25.003} & 0.017 \\
\hline & 25 & & 0.003 \\
\hline & 24.99 & & 0.013 \\
\hline \multirow{3}{*}{30} & 29.94 & \multirow{3}{*}{29.98} & 0.04 \\
\hline & 30.01 & & 0.03 \\
\hline & 30 & & 0.02 \\
\hline \multirow{3}{*}{35} & 34.58 & \multirow{3}{*}{34.86} & 0.28 \\
\hline & 34.98 & & 0.12 \\
\hline & 35.03 & & 0.17 \\
\hline \multirow{3}{*}{40} & 40.29 & \multirow{3}{*}{40.17} & 0.12 \\
\hline & 40.02 & & 0.15 \\
\hline & 40.2 & & 0.03 \\
\hline \multirow{3}{*}{45} & 45.36 & \multirow{3}{*}{45.22} & 0.14 \\
\hline & 45.1 & & 0.12 \\
\hline & 45.2 & & 0.02 \\
\hline \multirow{3}{*}{50} & 49.98 & \multirow{3}{*}{50.09} & 0.11 \\
\hline & 50.01 & & 0.08 \\
\hline & 50.3 & & 0.21 \\
\hline
\end{tabular}

From the results of the calculation is obtained that the PING sensor has a average of deviation is $0.043 \mathrm{~cm}$ and standard deviation $0.05 \mathrm{~cm}$ at a distance of $10 \mathrm{~cm}$.

\section{CONCLUSION}

From the results of the design, observation and testing of portable phototherapy device 


\section{Design of Portable Phototherapy using PL-S UVB Lamp for Psoriasis Therapy}

using the PL-S UVB lamps, then it can be concluded that every series works well according to that designed with a tolerance of $10 \%$. Ultraviolet radiation spectrum can penetrate the base layer of the dermis. Ultraviolet rays B can penetrate the base layer of epidermis skin.

\section{ACKNOWLEDGMENT}

Thank you for Lembaga Penelitian dan Pengabdian kepada Masyarakat (LPPM) Universitas Nasional and my collegues in Faculty of Engineering and Science, Universitas Nasional.

\section{REFERENCES}

1. Wang, S.-H., et al., Increased risk for incident thyroid diseases in people with psoriatic disease: a cohort study. Journal of the American Academy of Dermatology, 2019. 80(4): p. 1006-1012.

2. Augustin, M. and M.A. Radtke, Psoriasis: Epidemiology. Harper's Textbook of Pediatric Dermatology, 2019: p. 343-349.

3. Richard, E.G., The Science and (Lost) Art of Psoralen Plus UVA Phototherapy. Dermatologic clinics, 2020. 38(1): p. 11-23.

4. Zheng, Q., et al., Total glucosides of paeony for the treatment of psoriasis: A systematic review and meta-analysis of randomized controlled trials. Phytomedicine, 2019: p. 152940.

5. Perez, A., et al., Safety and efficacy of oral calcitriol (1, 25-dihydroxyvitamin D3) for the treatment of psoriasis. British Journal of Dermatology, 1996. 134(6): p. 1070-1078.

6. Raychaudhuri, S.K., E. Maverakis, and S.P. Raychaudhuri, Diagnosis and classification of psoriasis. Autoimmunity reviews, 2014. 13(4-5): p. 490-495.

7. Morgan, P., et al., UVB therapy: dermatology nursing considerations. Dermatology nursing, 1997. 9(5): p. 309-323.

8. Lapolla, W., et al., A review of phototherapy protocols for psoriasis treatment. Journal of the American Academy of Dermatology, 2011. 64(5): p. 936-949.

9. De Berker, D., et al., Comparison of psoralen-UVB and psoralen-UVA photochemotherapy in the treatment of psoriasis. Journal of the American Academy of Dermatology, 1997. 36(4): p. 577-581.

10. Šitum, M., et al., Benefi ts of Controlled Ultraviolet Radiation in the Treatment of Dermatological Diseases. Collegium antropologicum, 2014. 38(4): p. 1249-1253.

11. Narayanan, D.L., R.N. Saladi, and J.L. Fox, Ultraviolet radiation and skin cancer. International journal of dermatology, 2010. 49(9): p. 978-986.

12. FRANSISKA, A., S. HUSADA, and E. EFFENDY, THE DIFFERENCES OF DEPRESSIVE SYMPTOMS BY GENDER IN PEOPLE WITH PSORIASIS. 2018.

13. Wiatrowski, M. and N. Furfaro, Patient profiles in psoriatic disease: a case-based approach. Dermatology nursing, 2007. 19(5): p. S5-S5.

14. Malkin, R. and V. Anand, A novel phototherapy device. IEEE Engineering in Medicine and Biology Magazine, 2010. 29(2): p. 37-43.

\section{AUTHORS PROFILE}

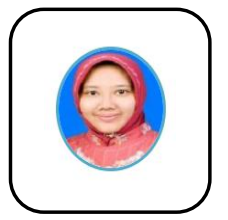

Fitria Hidayanti Ph.D. candidate at Faculty of Engineering, University of Indonesia. Assistant Professor at Engineering Physics Department, Universitas Nasional.

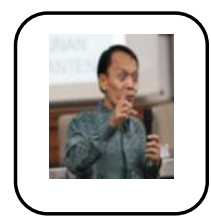

Sunartoto Gunadi Professor at Engineering Physics Department, Universitas Nasional.

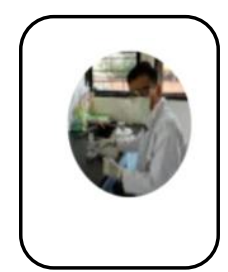

M. Syafaat Bachelor Degree at Engineering Physics Department, Universitas Nasional. 